\title{
Research on the Diversified Forms of Anime Game Medium
}

\author{
Yuqing Ji \\ Department of Animation school, Hebei Institute of Fine Art, Shijiazhuang Hebei, 050700, China
}

\section{Keywords: Alexander Petrov, Anime Game, Russian Animation, Medium}

\begin{abstract}
Media is everything, and everything is media, so media can not be found no time and nowhere. Those substances that can make people and people, people and things or things and things be connected are generalized media. In the animation design, there are many kinds of media, such as, glass, paper, walls, etc, and animation manifestation types are diverse. The medium of animation can be of any material, and its main function is to serve the animators1 imaginations, and animation media would be an exaggeration to the extreme that does not make the audience feel weird. Many Russian animations, such as Alexander Petrov's animation works created pioneering and experimental of the animation forms, and in Media pluralism Times, it has a profound impact on contemporary cartoons.
\end{abstract}

\section{Development of Animation Under Media Pluralism Background}

Media Pluralism Arrival. Media is Everything. In McLuhan's treatise, the media is everything, everything and all media ("The medium is the message"). Media people or things or make things happen bilateral relations. All media are thus relationship can happen with people. Such as pictures, books are eye extension, radio, music is extended ear, all kinds of hand tools are hand extended, clothing is the skin stretched, the wheels are extended foot. Media anytime, anywhere there. He believes that "As a technology, the watch is a machine, which according to the assembly line mode of production uniform seconds, minutes, hours and other units of time. After such a unified processing time separated from the rhythm of the human experience." clock as an important invention era of industrial civilization, reflecting a measure of human time and perception. [1]Time is a special kind of media support, while innovative technology continues to transform the time. "Different cultures different social

Concept of time, the human concept of time experiencing the natural time clock time after two stages, is to the new 'media time' transition. "' Medium is the message "because of the scale and form of a combination of human actions, media are playing for shaping and control; however, media content and use is a wide variety of content to form interpersonal media combination is virtually powerless, any media "content" makes us the nature of the medium. turn a blind eye, but this is very typical today, the industry did not realize what they are engaged is the business of International Business Machines Corporation it found that its business is not the manufacture of office equipment or business machines, but processing information. After that, it only the provision of a clear vision new voyage. profit General Electric Company acquired a large part by the manufacture of light bulbs and lighting systems, but the same as the American Telephone and Telegraph Company, its business is to transmit information. photoelectric, this media The reason did not attract attention, precisely because it does not "content." This makes it a very valuable example, we can use it to illustrate why people in the past did not study media until photoelectric trademark is used to play advertisements, It was noted that it is a medium. However, people's attention is not the electro-optic itself, but its "content" (actually another medium). photoelectric positive message is 
the message of the power industry, it is completely dispersed, inherent decentralization of photoelectric and power its use is separate from, but they eliminate the time difference when combined interpersonal and spatial differences, just as radio, telegraph, telephone and television, to to eliminate differences in the function of time and space is exactly the same, they are deeply involved in their own people are engaged in activities. All media are an extension of the body, or the conversion of material to various substances the body, so any media inquiry traitor All studies have contributed to other media.

Art Design News Media. Art and Design along with a time of change and progress of the times, and each time the development of science and technology, in a time of change into an art form with advances in technology to become more prosperous. Recalling the history of art and design development, we can see that the progress of science and technology for the creation of art and design had a profound impact: the formation of the theory of perspective in painting attributed to the development of science perspective; human anatomy as sculptures, drawings and other art provides a theoretical reference; progressive artists of color performance space, thanks to the development of the chemistry of pigment; and the birth of the art of photography thanks to the development of a Subsidiary of optical applications; optical principle of development so that the artist according to optical principles to analyze, organizations Totem association. All this reflects the development and progress of science and technology for the development of art and design to provide a boost.

Art Design medium factors, including new media and traditional media. New media is a relatively traditional media in terms of traditional art media mainly paper, prints, and many more two-dimensional work of art Zhen Jing towel. New media art and design using computer software to create, to express through radio, television, Internet and other media, the formation of a new form of artistic expression. 3D animation which is a typical representative.

Development of Painting under Media Diverse Backgrounds. Painting is a Reconstruction of the Real World. Painting is reconstructed on a plane media relations of the real world spatial structure and lighting features, painting reflects the particular society's view of man and nature. From Western painting, we can see different geographical and cultural world. Western painting exhibited bright colors, spatial relationships and light sensitive, there is a certain link with their natural and cultural environment. Nordic those picturesque town scenery, hills and fields have been reflected in paintings. World clear and clean, blue sky painter lived floating clouds, mountains with sprawling trees, fields covered with grass, food stands and elegant towns in outline church steeple and other buildings. [2]Whether or public buildings are elegant aristocratic mansion, decorated complicated, delicate sculptures. Painting is a form of human experience and the reproduction of the world, than to other forms of human language to express knowledge of the world, such as literature, philosophy also earlier. A cultural phenomenon in the world of painting to reconstruct the way in turn will affect the national awareness and use of the objective world of fashion. Make the pursuit of Europe since the Renaissance in painting accurately depicting nature, and promote the natural sciences, especially the development of physics and optics. Many of the great painters of the Renaissance, for example up to Vinci (Leonardo di ser Piero da Vinci, 1452-1519), both a painter and a scientist. China has always been lacking in the spirit of realism paintings, after the middle of the Ming Dynasty, the subject matter and the form of expression is becoming more rigid. Youwei presented at the beginning of the 20th century, "study painting, for all of the school's" advocates reform of Chinese painting, "In the main form of God does not take freehand, with colored circles draw is positive, but with pen crude Jane who was not sent" "membership in all trades and is painting, painting is not improved, the business no speak." Such a comment is not without reason. 
In modern times, another point of view, although against this interference pure rationalism tool of artistic expression, but it also adds a sense of the nature of art and social cognitive complexity.

Development of the Painting under Media Diverse Backgrounds. Historically, there are many material is used as the medium of painting, such as copper, stone, paper, leather, plastic, etc., based on ancient stone as a medium, most commonly used is the modern wood and cloth, paper. Stone Age is the embryonic period paintings, including rock as well as those painted on pottery Neolithic ornamentation. Inner Mongolia Yinshan Rock is one of the earliest rock art. There we first people for up to a million years or so created many such images, these images of the entire interconnected mountain turned into a 300 km-long gallery.

Animation Development under Media Pluralism Background. Basic Form of Animation is Painting. Simple to understand the word "animation" means, is that you can move the screen. Designers change the course of human and animal facial expressions, movements or objects drawn into a web of a single screen, and then put these single camera filmed a series of consecutive images, so that it becomes to produce a continuous change of the screen. Persistence of vision principle is the basic principle of the animation, the basic principle is the same film and television visual persistence principle. After study based on medical science shows that humans see objects .34 seconds after the object will disappear, this is the human "persistence of vision" features. According to this feature, within 0.34 seconds of continuous play two pictures, they will form a relatively smooth visual change. Thus, there are two standard in the choice of recording and playback speed of the picture: PAL system (primarily for television, 25 per record) and NTSC system (primarily for movies, records per 30). And because of the great animation work, in general, would choose "a film one" (recorded every second 24), "a film two" (recorded per 12) or "one shot three" (recorded every second 8) production methods, the most accepted human vision is "a shot one," but in order to save costs, many cartoon was "a beat two", "a film three", where "one shot three" is already a visual limit, In fact, if played fewer than 10 pictures per second, there will be a pause, just the general "one shot three" of animation in the role of setting, plot development and other aspects make amends. Thus, most animation preclude the use of "one shot two" format. Animation word in the English language as "animation", which means giving a picture of life. Compared with other art forms, "picture" here has apparently become the most basic form elements. Since it is a picture, then one of the sense of form and painterly plane on and other art forms, like the artistic charm of the cartoon plays a vital role, especially in experimental animation, which form the painting tends to become The main direction of the artist's exploration. At the same time, we also see a lot of countries directly involved in the cartoon painting master this art form of creation, their art style to the cartoon, which enhance the quality of the animation, prosperity animation form, played a very important role.

Animation Development under Media Pluralism Background. Early in twenty-five thousand years ago, humans had already begun to "move" had a desire, and try to capture human or animal movements, the best and earliest evidence of Stone Age cave is found in bison run analysis screen . There are a lot of this type of discovery, in a picture of the action has occurred displayed, people open up it is a set of actions simultaneously. For example, up to? Vinci golden ratio figure human limb arm, which means that the body's arms L bobbing action. Chinese painting masters, has been advocated Qiyun vivid, which is to show that "move" the desire of the paintings produced. It is these "move" the desire that prompted Europe to animate (make drawing on the graph moving up). Modern animation get really big development has benefited people to explore light and shadow. [3]Speaking of the pioneers of modern animation, had first mentioned the 17th century Jesuit River snow (Athanasius Kircher, 1602-1680). 1640, River snow invented the "magic lantern slide" (The Magic Lantern). This can be animated, but also the beginning of all movies. The so-called magic 
slide is a metal box, which put a wrong candle, metal box on each side Jian a small hole, cover the lens hole. A piece of glass painted patterns on the back of the lens, and the lens through a light through the glass, the pattern can be projected on the wall.

\section{Alexander Petrov and Works Manifestations Analysis}

Russian Animation Master Alexander Petrov. Russian Animation. Russian animation has a hundred years of glorious history, during which produced a large number of world-class masters works. Russian animation rise in the "stop-motion shooting method." With this method, the camera can - Grid - Grid to put scenes filmed. Home pay was a famous photographer, director Stark Popovich noticed this - method, then began working alone Jian animation production and creation. And in 1912 to show the world he created "Beautiful Liu Ka Nida" (The LBeautiful Leukanida), "the photographer of retaliation" (Revenge of the Kinematograph Cameraman) and other classic works. These works let the world first - time felt the three-dimensional art animation hidden force. 1979 creation complete "Star Trek," the release, kicked off the Russian animation development. Early 1930s, with the rise of the animation industry, creating the animation has started to become a profession, chaired official Soviet Soyuzmult Film studio was founded in Moscow in 1936, becoming the Soviets all animation artists, directors and the producer's home. Russia has attracted many of the best artists come to presence, these artists abandon national decree propaganda movies, children's film production investment. After that the Soviet government decided to promote the animation industry, so they started the animation studio. But at that time due to the influence of the Soviet Union coincided with a wave of formalist thinking, coupled with persons in charge of the film industry animation ideology and theory-oriented subjective interference, although the Soviet Union during this period has been a lot of animation to enhance the production capacity, but most On the artistic value is retrogression. However, this period has also emerged a lot of progressive thinking animation director, to create a lot of content in the form of a unique, role modeling outstanding animation.

1939 World War II broke out, the animation world pattern has changed, due to the effects of war broke the American monopoly on the animation industry sources, this time the American animation also began to decline. But Russia's animation authoring environment has ushered in another piece of circumstances. In order to strengthen its anti-fascist war, Russia emerged a large number of outstanding in the anti-fascist theme of animation, animators who with ironic writing style and content in the form of vivid animation greatly enhance the artistic creation value, and promote the development of animation creation. This also affected the trend after the animation, war, animators have absorbed a large number of excellent traditional folk culture at home and abroad combined with the essence of the myth of well-known fable, folklore combined in creative thinking socialist realism was innovation, it still created a familiar outstanding works. As 1948 tibolone Schaumburg Brothers (Thesisters Zinaida and Va Shu entina Brumberg) the "cost plus? Zaitsev" (Fedya Zaitsev), Cheaha Malinowski (Mikhail Tsekhanovsky, 1889-1965) of " The Tale of the Fisherman and the Fish "(MikhailTsekhanovskiy), 1954 Years" Frog Princess "(Princess Frog), LevAtamanov, (1905-1981) of" The Snow Queen "(The Snow Queen) and the like. From these works we can clearly feel the creative style of socialist realism embodies the fusion of realism and traditional culture, which we now can understand the concept creator and artistic creation in the beginning. The content is carried out diversified development, the creators do not willing straightforward, but full of its own national characteristics and political overtones, including a true portrayal of society and the dark side of social discontent criticism. Soviet animation maestro Ivanov ten thousand promise of well-known works, "long snake peaks pony." 
Alexander Petrov. Alexander Petrov is a Russian animation director, animator, born in Yaroslavl, who won the Oscar for best animated short film award. • 1957 Alexander Petrov was born on July 17, Yaroslavl State countryside, and later living in the capital of Yaroslavl State Yaroslavl. He studied art at the State Film and Television Academy and the Moscow Higher School under the tutelage of renowned playwright and director animation master Yuri • Norstein.

Alexander Petrov's work style from the late 1980s began to develop, with a strong romantic realism style. Animated characters, animals and landscapes are very realistic style has manifested. For example, in "Old Man," Alexander Petrov also described • Fisherman dream swordfish with his leisurely among the sea and sky together. Petrov's animated classic literary works are to be deemed animated themes, with a strong personal style. If Petrov drawing method is peculiar to him, then in the creation of his paintings is his unique way, he is with the fingertips stained glass paint on the surface of animation. Fingers stained with oil paint on the glass, not only makes the film even more shocking, but also so that each cell can become independent picture a beautiful painting, with a very strong performance of strong intensity. Petrov considered easier to paint with your fingers, you can draw faster, but also want to draw what to draw what is shared between the mind and finger painting of a shortcut, a way is the most direct. When Petrov performed using different levels of glass production, shooting with a camera, he tends to make the characters on one screen, while making the background picture on another layer, light layer by layer through the glass finished shooting the first towel Zhen After the picture, he again through wet paint on the glass is adjusted to take the next towel Zhen screen. [4] Petrov glass painting really is a tree Wonderful animation, he insisted on a 15-year period with a finger stained with dye on a glass painting way to show their artistic places seeking its own form has enough people admire.

Alexander Petrov Works. "Cow" (1989). 1989 • Alexander Petrov completed the first animated work, "cow" (TheCow, as shown in Figure 3-5), which is adapted from the Soviet writer Andrei Platonov • (Andrei Platonov, 1899-1951 ) works, and won the Oscar for Best Animated Short Film Award nomination. Although it is early to make this cartoon - Alexander Petrov, the distinctive painterly been impressive, every par extracted separately, are regarded as fine paintings. Since then, in addition to the work won a gold medal at the 3rd Hiroshima International Animation Festival, also in Varna, Bulgaria, Ottawa Animation Festival, won the grand prize at the Berlin Film Festival. Russia, a country next to the tracks, home to a normal family of three. The boy's memory, and they had a cow and its children lived quiet wonderful day, a cow in cattle by his father used both as arable land, consumption of milk and to provide for them. Later, his father sold the calf, cows in a time of grief labors, while the father is not, make a series of crazy action at the boy's witness, then, disaster coming. Thus, cows, calves, trains and the like plowing into intent fixed in the boy's mind, often reminiscent, sweet and sad feelings always exist floating his mind. Works depict boys in coolies and milk witnessed water to maintain the livelihood of a family of three cows in calf was sold after his father, gradually out of control, eventually rolling train. Video from the perspective of innocence, exudes a rich sense of melancholy and dreamy, laid Petrov images look, plus simple story strong humanitarian spirit, so this debut blockbuster.

Stunning beauty in the film, some just can not be expressed in words, all clips emotional: his short films, in their daily lives of most ordinary things can be transformed into a delicate pass Petrov beautiful animation. In this short film, in less than ten minutes, hardly any dialogue, Petrov produced a very fascinating story, with almost unreal atmosphere in each scene infiltration mission audience feel is sadness and nostalgia. The film was heartbreaking, but it is also encouraging and enrich the audience's heart. Soviet art has always been known for realism. The "cow" It is a realistic approach to the main works. First Watch, the audience will think this is a master of American 
realism • Andrew Wyeth (Andrew Wyeth, 1917-2009) picture: the vast background, people and things are showing mysterious and lonely atmosphere. He used the technique of glass painting, showing the Soviet realism style. Because the combination of people and the background with frosted glass paint on moving up, showing nothingness floating shock similar to photo realism there because it seems dreamlike, she impressed the audience.

"Making Strange Dreams of Man" (1992). Then Alexander Petrov in Yaroslavl (Yaroslavl) Panorama animation film company was founded, and was completed in 1992. "doing weird dream man" (The Dream of a Ridiculous Man, as shown in Figure 3-6), which is adapted Since Dostoevsky also Ostrovsky (Fyodor Dostoevsky, 1821-1881) of "Crime and Punishment" (Crime and Punishment), describe a life of despair and ready to commit suicide man, because with a little girl accidentally encounter, while heavy eligible freshmen. "Doing weird dream man," published in the April 18 fight in "Writers Diary", is Dostoevsky also Khodorkovsky in his later years writing an allegorical short stories. Absurd people were surrounding the taunts from childhood, but he does not blame others, but they think it is very cute, but he is melancholy, because only one person knows the truth. Ridiculous Man's dream for a better world has gone from pure to dirty ugly shift change, people change absurd in reality is the world's assimilated him, and dreams of changing his sullied the world. Compare this actual situation so that readers will have to dream dreams of the world is also made to compare, and then found that the author is full of religious feeling of profound allegorical philosophizing. Because the process fallen dream world can not be ignored, "the Bible" mark. If people wake up after the absurd embarked on the road of redemption in the real world, then look for the little girl's move once again confirms: Redemption from suffering begins. At this time, the theme of suffering and redemption echoes earlier, deepen. Readers also finally understand the suffering of children carrying the image of the suffering of the world map, but to her rescue, but also symbolizes the human being took the road of self-redemption. Ridiculous people dream before been given the image of a love and tolerance, the dream of utopian fantasy world is full of wonderful. The absurd man changes, the world's fall, have proved false and vain fantasy.

Many viewers thought the Tuo Dostoevsky adaptations of skeptical, a few talented director to be able to put his work fully digested and scale appropriately. However, "doing strange dreams of man" Petrov is a favorite work, very difficult despite the adaptation of this work together, but "doing strange dreams of man" in front of the finished product on our watch time, you will find the film's visual impact on people, is no doubt a great work of art. It will combine the performance of realism and fantasy leaching drops every minute, the film's themes and creative combination of stunning. Of course, this work is the most important practical significance combines different art forms to express their ideas. This is a real work of art touches people's heart and soul, in animation history has left an indelible mark, it is practical significance and symbolism have unparalleled. "Doing weird dream man," most of the time wandering between Petrov fantasy, not only dozens of beautiful scene change, show a high degree of production techniques. [5] Petrov delicate precision and strong personal emotion in this movie by flashing strokes painting surreal dream to link up to the world in the film's climax compassion carefree erupted. The film won a number of awards at the Annecy Animation Festival in France, Ottawa, Tampere, Finland, Portugal Espino, Portugal Vila Kindi, Hiroshima and other parts of the world.

Old Man and Sea(2000). In 1997, Alexander Petrov to Canada • development, 40 years old, he overcame the difficulties caused by the environment and technology, with their wisdom will be the famous American novelist Ernest Hemingway macro magnum opus "Old Man" is changed to a 20-minute animated short film onto the screen and become one with super shocking movie, plot twists, and won the Oscar for Best Animated Short Film Award. This work demonstrated a high 
degree of technical level, completely glass creation, Alexander - Petrov with his fingertips when applied as a paint brush, and he is the only use their fingertips to smear paint animators in the world, This creative way to give the audience the film can be created by the new visual effects with the painting.

In the "Old Man", almost every towel infidelity can independently become a beautiful painting, in the performance of its magnificent sea spirit, Haitian integration level, with a very strong performance strength strong color over structured and heavy ink rendering, people feel lonely world of vast and the elderly. In terms of the performance of the facial expression, the same way as glass painting with a very prominent feature, though the facial details are not clear, but the artist's deep skill forced Xu paste the characters expressions such as health. Petrov will concentrate on the works of Hemingway 22 minutes of animated films, with different levels of glass for production, production figures on the floor, while in another layer of the production background, lighting a shot through the glass layer by layer in Zhen screen, then he wet through stained glass on the control to shoot the next frame. Its extraordinary difficulty, two and a half long, arduous creative life, always because of "Old Man," this touching story fascinated him. Petrov 9-12 inches in the production of the movie is an expert, this time in order to change the glass painting he had to use 30 inches. Big screen movies requires that he must be careful and meticulous production, otherwise a little oversight on the screen will be magnified. "Old Man" movie film using $70 \mathrm{~mm}$, than the traditional film footage for a whole five times to seven times, and therefore, the film slightest mistake can be infinitely expanded. In the film, the process is repeated 29, 000 times, the hard work going on for nearly three years. 7 and the film process old man and the sea, fish struggle precisely Petrov vivid portrayal of the hard work. "Old Man" was highly praised around the world and won the Oscar for Best Animated Short Film Award and international animation festival award for best animated short film. More so numerous animators have into this manifestation go.

Alexander Petrov Works - Study a Manifestation of "Old Man" Case. Glass as a medium of painting animation painting is a traditional art, in today's fast-paced development of society, how to make this ancient discipline revitalized, is a topic worthy of in-depth research. [6]Cartoon "Old Man" by modern technology aids and means to make painting and animation combine to promote the art form of diversification of development objectively, the two forms of art paintings and animations that blend natural, perfect, produce oil painting, animation language harmonious duo, not only in the high-tech means.

\section{Animation Diversified Forms of Media Research}

Throughout the 20th century, the race riding Cong feature film production skills (eel techniques) dominated the animation world, "Disney style" is considered to be the perfect interpretation of 2D animation. Then, on animation history has emerged a number of different aesthetic point of view, the artists also have been in use for a variety of media animation.

Concept of time, the human concept of time experiencing the natural time clock time after two stages, is to the new 'media time' transition. "' Medium is the message "because of the scale and form of a combination of human actions, media are playing for shaping and control; however, media content and use is a wide variety of content to form interpersonal media combination is virtually powerless, any media "content" makes us the nature of the medium. turn a blind eye, but this is very typical today, the industry did not realize what they are engaged is the business of International Business Machines Corporation it found that its business is not the manufacture of office equipment or business machines, but processing information; After that, it only the provision of a clear vision new voyage. profit General Electric Company acquired a large part by the 
manufacture of light bulbs and lighting systems, but the same as the American Telephone and Telegraph Company, its business is to transmit information. photoelectric, this media The reason did not attract attention, precisely because it does not "content." This makes it a very valuable example, we can use it to illustrate why people in the past did not study media until photoelectric trademark is used to play advertisements, It was noted that it is a medium. However, people's attention is not the electro-optic itself, but its "content" (actually another medium). photoelectric positive message is the message of the power industry, it is completely dispersed, inherent decentralization of photoelectric and power its use is separate from, but they eliminate the time difference when combined interpersonal and spatial differences, just as radio, telegraph, telephone and television, to to eliminate differences in the function of time and space is exactly the same, they are deeply involved in their own people are engaged in activities. All media are an extension of the body, or the conversion of material to various substances the body, so any media inquiry traitor All studies have contributed to other media.

Alexander Petrov's work style from the late 1980s began to develop, with a strong romantic realism style. Animated characters, animals and landscapes are very realistic style has manifested. For example, in "Old Man," Alexander Petrov also described • Fisherman dream swordfish with his leisurely among the sea and sky together. Petrov's animated classic literary works are to be deemed animated themes, with a strong personal style. If Petrov drawing method is peculiar to him, then in the creation of his paintings is his unique way, he is with the fingertips stained glass paint on the surface of animation. Fingers stained with oil paint on the glass, not only makes the film even more shocking, but also so that each cell can become independent picture a beautiful painting, with a very strong performance of strong intensity. Petrov considered easier to paint with your fingers, you can draw faster, but also want to draw what to draw what is shared between the mind and finger painting of a shortcut, a way is the most direct. When Petrov performed using different levels of glass production, shooting with a camera, he tends to make the characters on one screen, while making the background picture on another layer, light layer by layer through the glass finished shooting the first towel Zhen After the picture, he again through wet paint on the glass is adjusted to take the next towel Zhen screen. Petrov glass painting really is a tree Wonderful animation, he insisted on a 15-year period with a finger stained with dye on a glass painting way to show their artistic places seeking its own form has enough people admire.

\section{Stone and other Forms of Expression for the Media Research}

Animated original movie is the initial stage of development, it is the human attempt to show movement forms an important part of the course. Human mastered the performance and after pictures have been living in the pursuit of performance movement, through various forms of recorded images showing the human subconscious performance object motion and the time course of desire, animation 9 of this period is the stone for the media An animated representation.

Twenty-five thousand years ago Stone Age, in the mountain caves of Altamira in northern Spain, it was discovered that a large number of Paleolithic mural. These mural paintings from the point of view of method and style can be divided into five periods interrelated, also belong to the latest cultural Margaret Sterling (approximately 20000-120000 years ago), with a variety of paint murals depicting many animals image, such as bison, deer and pigs, about two meters vivid and vibrant. Which has a head of wild boar running attracted attention: In addition to vivid, intriguing is that wild boar leg was drawn repeated several times, which makes the original still image generated visual dynamic. It is long been recognized as the first "movie phenomenon." To Egypt's pharaohs, painters were on huge pillars of the temple, exploded pictorial image of God's welcome action 
series of performance, when Pharaoh speeding carriage ride from beside the temple pillars and outdated, these images will "move up" if God welcome the arrival of the Pharaohs. French archaeologist Purdue even mom (Prudhommeau) in 1962 study based on reports that 25,000 years ago, Stone Age cave paintings of bison run analysis on the series, and is a human attempt to abuse of a pen or coagulation solution action stone capture. [7]On a map of the action occurs at different times of painting together, this "simultaneous," the concept of indirect display of human "action" desire. Others, such as the Egyptian tomb paintings, continuous action Grecian bottle exploded picture is similar. There DaVinci golden ratio segmentation map drawn four arms, showing his hands up and down swinging movement;? History of Chinese painting, the artist has given life to a static painting tradition, such as "Six theory" advocated Qiyun vivid, Ghost Story "fairy painting" characters out of the reel, etc. (although rely on imagination to make up dynamic).

\section{References}

[1] Xue Feng, Yu Jie .episode animated short film parsing [M] Beijing: China Film Press, 2010.

[2] Wu Jun. animated audiovisual language [M] Beijing: China Water Power Press, 2010.

[3] Wang Ping, YIN Jun animated audiovisual language [M]. Nanjing: Jiangsu Science and Technology Publishing House, 2010.

[4] Xue Feng. animated story with an animated pre-sets of the innovations of research [M]. Nanjing: Nanjing University Press,2009.

[5] (English) Introduction to Animation Maureen [M] Beijing: China Youth Press, 2009.

[6] Zhao Qian. boutique animated film analysis [M] Chongqing:? Chongqing University Press, 2010.

[7] Fuguan .Chinese Art Spirit [M] Shanghai: East China Normal University Press, 2001. 